ACADEMIA ROMÂNĂ Roum. Chim.,
Revue Roumaine de Chimie
http://web.icf.ro/rrch/

\title{
IN SILICO INVESTIGATION APPLIED IN PHYSICAL, CHEMICAL PROPERTIES AND VIBRATIONAL ANALYSIS OF 1.3.4-THIADIAZOLE DERIVATIVES
}

\author{
Nabila AOUMEUR, ${ }^{a}$ Noureddine TCHOUAR, ${ }^{a}$ Salah BELAIDI,,${ }^{b}{ }^{*}$ Dalal HARKATI ${ }^{b}$ \\ Houmam BELAIDI ${ }^{\mathrm{b}, \mathrm{c}}$ and Abderrahmane ROUANE ${ }^{\mathrm{a}}$
}

\begin{abstract}
${ }^{a}$ Laboratory of Modeling and Optimization of Industrial Systems, University of Science and Technology of Oran-Mohamed Boudiaf(USTO-MB) 31036, Algeria

${ }^{\mathrm{b}}$ Group of Computational and Medicinal Chemistry, LMCE Laboratory, University of Biskra, BP 145 Biskra 07000, Algeria ${ }^{\mathrm{c} I n s t i t u t ~ d e s ~ S c i e n c e s ~ C h i m i q u e s ~ d e ~ R e n n e s, ~ U M R ~} 6226$ CNRS-Université de Rennes 1, Campus de Beaulieu, 35042, Rennes Cedex, France
\end{abstract}

Received July 14, 2017

The equilibrium geometries of 1,3,4-thiadiazole derivatives have been determined and analyzed at DFT level employing B3LYP/6-31G(d) basis set. The molecular electrostatic potential surface (MESP) that reveals centers of reactivity of the molecule and substitution effects of the molecular system have been studied using the HSAB principle (Hard Soft Acid and Base).Results such us, fundamental vibrational modes, ${ }^{1} \mathrm{H}$ NMR isotropic chemical shifts, frontier orbital energies (HOMO, LUMO), band gap energy, dipole moments, net charges are reported and discussed in terms of reactivity of 1,3,4-thiadiazole derivatives. The HOMO and LUMO analysis were used to elucidate information regarding charge transfer within the molecule. Isotropic chemical shifts were calculated using the Gauge-Independent Atomic Orbital (GIOAO) method. Finally, a comparison between the experimental data and the calculated results appeared a good agreement and show exceptional reactivity.

\section{INTRODUCTION}

Heterocyclic compounds are cyclic compound with the ring containing carbon and other element, the component being oxygen, nitrogen and sulphur. Several five membered heteroaryl systems with three heteroatoms at symmetrical positions, such as 1,3,4thiadiazole, have attracted continuous interest over the years due to their interesting pharmacological activities. $^{1-3}$ 1,3,4-Thiadiazole is a versatile framework that acts as a "hydrogen binding domain" and as a "two- electron donor system". ${ }^{4}$ It is a basic pharmacophore for a wide variety of biological activities, including antibacterial properties. 1,3,4thiadiazole can behave as the bio-isosteric replacement of the thiazole moiety, which can be found in the structure of third and fourth generation cephalosporins. Therefore, 1,3,4-thiadiazole can be successfully used in antibiotic preparations. ${ }^{4,5}$

The most studied regioisomeric form of the thiadiazole series, is 1,3,4-thiadiazole and its dihydroderivatives. ${ }^{6,7}$ These heterocyclic systems constitute the active part of several biologically active compounds (Acetazolamide, Methazolamide, Sulfamethizole, ${ }^{1,2}$ Glybuzole $^{8}$ etc.) and exhibits a wide range of therapeutic activities such as antimicrobial, ${ }^{9-14}$ diuretics, ${ }^{1}$ anti-leishmanial, ${ }^{15}$ antiulcer, antimycobacterial, ${ }^{9}$ anti-inflammatory, ${ }^{16}$ free radical scavenging, ${ }^{17}$ anticonvulsant, ${ }^{18,19}$ anticancer ${ }^{20}$ and antidepressant. ${ }^{9}$

\footnotetext{
*Corresponding author prof.belaidi@gmail.com
} 
In addition, some $\mathrm{N}$ - or S-substituted bearing aryl groups or heterocyclic motifs possess excellent biological activities. ${ }^{21,22}$ Therefore, the 1,3,4-thiadiazole derivatives in organic synthesis and medicinal chemistry represent a remarkable class of molecules. They have an impressive attention to reinforce kinase inhibitory activity, which is an intense area of investigation in antitumor research. ${ }^{21}$

For our theoretical study, we carried out calculations using specific software to determine difference in molecular geometry, electronic properties and energy of 1,3,4-thiadiazole derivatives using DFT method (density functional theory) (Fig. 1).

The theoretical calculation of vibrational properties is used to understand the spectra's of large number of donor-acceptor systems. Consequently, these calculations ascertained that the structure was stable (no imaginary frequency). DFT method is usually found to be a strong and accurate method for describing low-lying excited states of conjugated molecules and has consequently been applied to solve countless chemical and physical problems depending on the aim of the theoretical study.

The present work deals with reactivity and spectroscopic studies (NMR, IR) of 1,3,4thiadiazole derivatives employing the DFT method with $6-31 \mathrm{G}(\mathrm{d})$ as basis set. A comprehensive investigation of geometrical and electronic structure along with molecular electrostatic potential (MESP) surface and contour map may lead to better understanding of structural and spectral characteristic of the title compound under investigation. The Milliken analysis has also been carried out to elucidate information regarding the charge transfer within the molecule.

\section{MATERIALS AND METHODS}

\section{Experimental}

Materials used in this article were prepared from Fluka and Aldrich companies, all solvent and reagents were used without extra purification (purity 98\%), but solvents were purified with standard methods. Chromatographic analysis of the products was performed on Merck 60F254 silica plates. After elution, the products are revealed by Ultraviolet $(\lambda=254 \mathrm{~nm})$ or by iodine.

All compounds were known and identified by comparison of their physical and spectroscopic data with those of authentic samples. Melting points were measured on Electrothermal 9100 apparatus.

Synthesis of 2-amino-5- (3-chlorobenzo [b] thien-2-yl) -1,3,4-thiadiazole (1)

IR spectroscopy $\left(v_{\mathrm{cm}-1}: \mathrm{KBr}\right): 1565(\mathrm{C}=\mathrm{C})$, $1634(\mathrm{C}=\mathrm{N}), 3017\left(\mathrm{C}-\mathrm{H}_{\mathrm{ar}}\right)$ and $3310(\mathrm{NH} 2)$.

${ }^{1} \mathrm{H}_{-N M R}{ }^{1}\left[\delta(\mathrm{ppm})\right.$, DMSO- $\left.\mathrm{d}_{6}\right]: 7.50-8.30(\mathrm{~m}$, $6 \mathrm{H}, \mathrm{H}-4, \mathrm{H}-5, \mathrm{H}-6$ and $\mathrm{H}-7$ benzothiophene- $\mathrm{H}$, $\mathrm{NH}_{2}$ ).

Synthesis of 5-(3-chlorobenzo[b]thien-2-yl)-2(N-phenylamino)-1, 3, 4-thiadiazole (2)

IR spectroscopy $\left(v_{\mathrm{cm}-1}: \mathrm{KBr}\right): 1598(\mathrm{C}=\mathrm{C}), 1610$ $(\mathrm{C}=\mathrm{N}), 3049(\mathrm{C}-\mathrm{H}$ ar $)$ and $3214(\mathrm{~N}-\mathrm{H})$.

${ }^{1} \mathrm{H}_{-N M R}{ }^{1}\left[\delta(\mathrm{ppm})\right.$, DMSO-d $\left.{ }_{6}\right]:$ 77.10-7.42 (m, $7 \mathrm{H}$, phenyl $\mathrm{H}, \mathrm{H}-5$ and $\mathrm{H}-6$ benzothiophene), 7.928.18 (2d, 2H, H-4 and H-7 benzothiophene), 11.00 (s, 1H, NH).

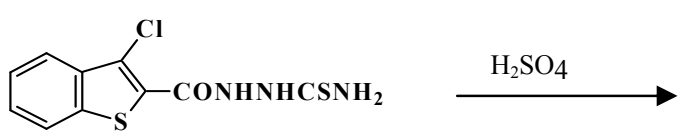

$4 \mathrm{~h}$

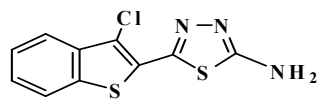

A C T (1)

Scheme 1 - Formation of ACT by reacting thiosemicarbazide acid.
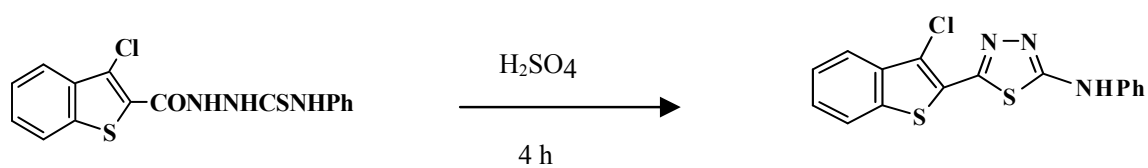

NPHACT (2)

Scheme 2 - Formation of NPHACT by reacting phenylthiosemicarbazide acid. 

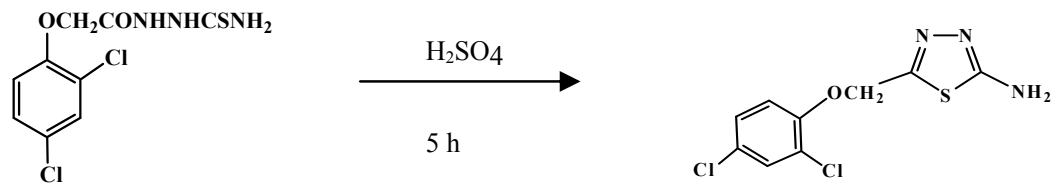

ADMT(3)

Scheme 3 - Formation of ADMT by reacting (2.4-dichlorophenoxy)acyl thiosemicarbazide.
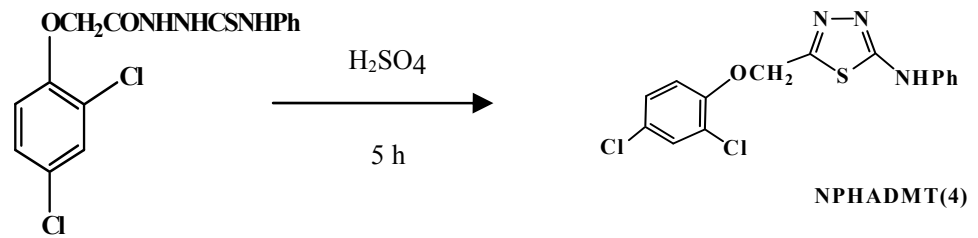

Scheme 4 - Formation of NPHADMT by reacting 1-[(2,4-dichlorophenoxy)acyl]-4-phenyl thiosemicarbazide.

Table 1

Organic parameters of synthesized 1,3,4-thiadiazoles

\begin{tabular}{c|c|c|c|c|c}
\hline Comp. & $\begin{array}{c}\text { MM } \\
(\mathbf{g} / \mathbf{m o l e})\end{array}$ & $\begin{array}{c}\text { Melting point } \\
\left({ }^{\mathbf{C}}\right)\end{array}$ & TLC Rf & Product & $\begin{array}{c}\text { Yield } \\
(\%) \mathbf{a}\end{array}$ \\
\hline 1 & 271.50 & $162-163$ & 0.60 & yellow crystals & 67 \\
2 & 329.99 & 156 & 0.45 & yellow crystals & 80 \\
3 & 247.97 & 156 & 0.37 & yellow crystals & 70 \\
4 & 351.00 & 98 & 0.37 & brown powder & 75 \\
\hline
\end{tabular}

a Isolated yields

TLC: Thin layer chromatography

TLC $R_{\mathrm{f}}(1)$ : (Hexane-Ethyl acetate: $3 / 1$ ).

TLC $R_{f}(2)$ : Petroleum ether-Ethyl acetate: $\left.5 / 1\right)$

TLC Rf (3): 0.37 (Hexane - Ethyl acétate : $3 / 1$ ).

TLC Rf (4): (Petroleum ether - Ethyl acetate: 4/1).

Synthesis of 2-amino-5-[(2, 4-dichlorophenoxy) methyl]-1,3,4-thiadiazole (3)

IR spectroscopy $\left(v_{\mathrm{cm}-1}: \mathrm{KBr}\right): 1582(\mathrm{C}=\mathrm{C}), 1660$ $(\mathrm{C}=\mathrm{N}), 2977(\mathrm{C}-\mathrm{H}$ al), $3090(\mathrm{C}-\mathrm{H}$ ar) and 3200$3433\left(\mathrm{NH}_{2}\right)$.

Synthesis of 5-I(2,4-dichlorophenoxy)méthyl)2-(N-phenylamino)-1,3,4-thiadiazole (4)

IR spectroscopy $\left(v_{\mathrm{cm}-1}: \mathrm{KBr}\right): 1557(\mathrm{C}=\mathrm{C}), 1637$ $(\mathrm{C}=\mathrm{N}), 3019(\mathrm{C}-\mathrm{H}$ al $), 3064(\mathrm{C}-\mathrm{H}$ ar $)$ and 3193$3266(\mathrm{~N}-\mathrm{H})$.

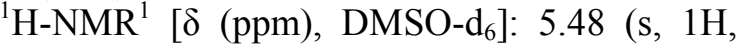
$\mathrm{OCH} 2), 7.27(\mathrm{~s}, 1 \mathrm{H}, \mathrm{NH}) 7.31-7.57(\mathrm{~m}, 8 \mathrm{H}$, phenyl C-H).

\section{Computational calculations}

All calculations for the 1, 3, 4-thiadiazole derivatives are performed by HyperChem $8.08,{ }^{23}$ Gaussian 09 program package. ${ }^{24}$ Firstly, we realized the calculation of some geometric and electronic parameters, using DFT method with the B3LYP, ${ }^{25}$ which combines trade $\mathrm{Becke}^{26}$ change-correlation with Lee, Yang, and Parr ${ }^{27}$ corrected functional by using 6-31G (d) basis sets, ${ }^{28}$ the chemical structure evaluated by quantum theoretical method. This work also involves calculation of 3D MESP surface map and 2D MESP contour map to reveal the information regarding charge transfer within the molecule. ${ }^{29-31} \mathrm{In}$ addition, HOMO, LUMO, energy gap ionization potential (I), electron affinity (A), electrophilicity index (w), chemical potential (l), hardness (g), softness (S) and vibrational spectrum of the title compound were calculated at the B3LYP/6-311G (d) level. Finally the Nuclear Magnetic Resonance (NMR) chemical shifts were performed using Gauge Independent Atomic Orbital (GIAO) method. ${ }^{32,33}$

\section{RESULTS AND DISCUSSION}

\section{Geometric and electronic structure of 1,3,4-thiadiazole}

The optimized molecular structure of these compounds: 2-amino-5(3-chlorobenzo[b]thien-2- 
yl-1,3,4-thiadiazole (ACT); 5-(3-chlorobenzo[b]thien-2-yl)-2(N-phenylamino)-

1,3,4thiadiazole (NPHACT);

2-amino-5-[(2,4-dichlorophenoxy)methyl]1,3,4-thiadiazole(ADMT);5-[(2,4-dichlorophenoxy) methyl]5-[(2,4-dichlorophen-2(N-phenylamino)1,3,4-thiadiazole(NPHADMT); were calculated by DFT/B3LYP level with 6-31G(d) basis set (Fig. 1) along with atom numbering.

The frontier molecular orbitals (HOMO and LUMO) are the main orbital participating in chemical reactions and they also used for predicting the most reactive position in $\pi$-electron systems. The HOMO energy describes the ability of electron giving, LUMO describes the ability of electron accepting, and the energy gap between HOMO and LUMO describes the molecular chemical stability ${ }^{34}$ and it is important parameter in determining molecular electrical transport properties because it is a measure of electron conductivity.

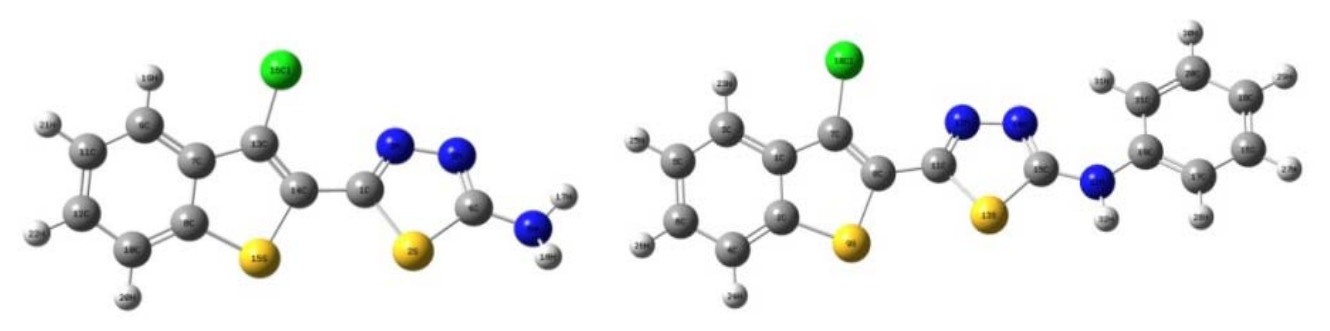

$\operatorname{ACT}(1)$

NPHACT (2)

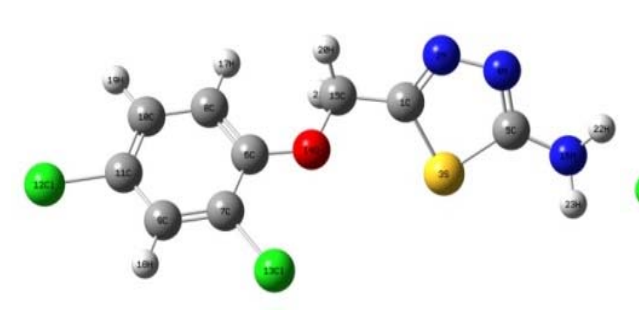

$\operatorname{ADMT}(3)$

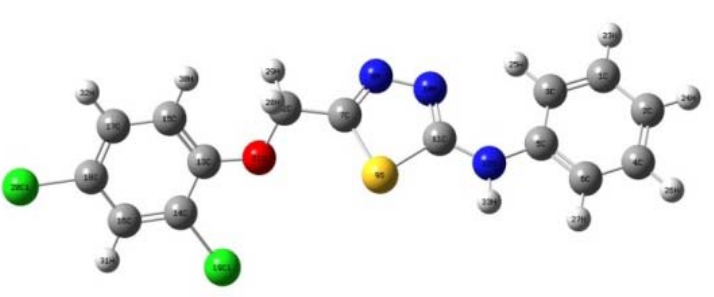

NPHADMT (4)

Fig. 1 -3D structure of 1,3,4-thiadiazole derivatives.

Table 2

Electronic parameters of 1,3,4-thiadiazole systems

\begin{tabular}{|c|c|c|c|c|c|c|}
\hline Comp. ID & Nomenclature of compound & $\begin{array}{c}\text { Total } \\
\text { Energies } \\
\text { (a.u.) }\end{array}$ & $\begin{array}{c}\mathbf{E}_{\text {номо }} \\
(\mathrm{eV})\end{array}$ & $\begin{array}{c}E_{\text {LUMO }} \\
(\mathrm{eV})\end{array}$ & $\begin{array}{c}\Delta \mathbf{E} \\
(\mathrm{eV})\end{array}$ & $\begin{array}{c}\mu \\
\text { (Debye) }\end{array}$ \\
\hline ACT & $\begin{array}{c}\text { 2-amino-5- (3-chlorobenzo [b] thien-2-yl- } \\
\text { 1,3,4-thiadiazoles }(1)\end{array}$ & -1805.478 & -5.825 & -1.773 & 4.051 & 3.55 \\
\hline NPHACT & $\begin{array}{l}\text { 5- (3-chlorobenzo [b] thien-2-yl) -2- }(\mathrm{N}- \\
\text { phenylamino) -1,3,4-thiadiazole }(2)\end{array}$ & -2036.530 & -5.589 & -1.846 & 3.743 & 3.60 \\
\hline ADMT & $\begin{array}{c}\text { 2-amino-5-[(2,4dichlorophénoxy)methyl]- } \\
\text { 1,3,4-thiadiazoles(3) }\end{array}$ & -1950.188 & -6.353 & -0.929 & 5.424 & 2.73 \\
\hline NPHADMT & $\begin{array}{c}\text { 5-[(2,4dichlorophenoxy)methyl)- } \\
\text { 2(Nphenylamino)-1,3,4-thiadiazole(4) }\end{array}$ & -2136.239 & -5.835 & -1.089 & 4.745 & 3.00 \\
\hline
\end{tabular}


In order to investigate the energetic behavior and dipole moment of these compounds, optimizations were performed. Theoretical calculations included the total energy, HOMOLUMO energies, energy gap, and dipole moment using B3LYP/6-31G (d) level. Results obtained are listed in Table 1, and it reveals the energy gap reflect the chemical activity of the molecule. In addition, the total energies for the studied compounds (1-4) are calculated by DFT ($1805.478, \quad-1950.188, \quad-2036.530,-2136.239)$ respectively. The smallest value of calculated energy is $(-2136.239$ a.u.) and the highest value is (-1805.474 a.u.) of 1,3,4-thiadiazole derivatives. Also, we see that the value of total energies is relatively negative. ${ }^{35}$ The energy value of HOMO is computed as $(-5.589 \mathrm{eV})$ and LUMO as $(-1.846$ $\mathrm{eV})$, therefore the energy gap value is $(3.743 \mathrm{eV})$ and the dipole moment is (3.60 Debye) for NPHACT compound.

Lower value in the HOMO and LUMO energy gap explains the eventual charge transfer interactions taking place within the molecule from HSAB (Hard Soft Acid and Base) principle, the lowest energetic gap allows an easy flow of electrons which makes the molecule soft and more reactive which means that compound $\mathbf{2}$ is the most reactive of 1,3,4-thiadiazole derivatives. ${ }^{36}$

The dipole moments computed by the DFT method indicate that each studied molecule seems to be polar (hydrophilic), and may interact with its environment strongly in solution. ${ }^{37}$ The donor sites of proton interact with the oxygen atom of water and the acceptor sites of proton interact with the hydrogen atom. These interactions of weak energy are generally reversible in particular between messengers and receivers. ${ }^{38-40}$

The contour plots of the $\pi$-like frontier orbital for the ground state of the compounds 1-4 are shown in (Fig. 2). Compound 2, shows that it is likely to exhibit an efficient electron transfer from benzo[b]thiophene group of the HOMO to the $(\mathrm{N}$ phenylamino) group of the LUMO if electronic transitions occur. From the plots, we can observe that the LUMO mainly concentrates on benzo[b]thiophene and thiadiazole ring regions with some delocalization along (N-phenylamino), whereas, the HOMO distributes over the whole molecule. For compound $\mathbf{3}$, the HOMO is delocalized at the amino- (1,3,4-thiadiazole), whereas the compound $\mathbf{4}$, is delocalized at the $(2,4-$ dichlorophenoxy) methyl for the HOMO and LUMO occurs through $\pi$-conjugated.

\section{Molecular electrostatic potential surface (MESP)}

The molecular electrostatic potential surface MESP is a piece of electrostatic potential mapped onto the iso-electron density surface, ${ }^{41}$ the importance of the MESP lies in the fact that at the same time it shows the molecular size and form whether positive, negative and neutral electrostatic potential areas in terms of the electrostatic surface, which illustrate the investigation of the molecular structure with its physicochemical properties relationships. ${ }^{42-44}$

The MESP surface map and contour map of 1,3,4-thiadiazole derivatives (Fig. 2) display the two regions characterized by red color (negative electrostatic potential) around the two cyclic nitrogen and oxygen atoms which expound the ability for an electrophilic attack on these positions, also by blue color (positive electrostatic potential) around the hydrogen atoms which explain that these regions are susceptible for a nucleophilic attack. Besides, the regions near the chlorine atoms are more orange or yellow, which indicates a less negative potential than the previous one. Finally, for the green color located between the red and blue regions explain the neutral electrostatic potential surface. The variation in electrostatic potential produced by a molecule is largely responsible for binding of a drug to its active sites (receptor), as the binding site in general is expected to have opposite areas of electrostatic potential. ${ }^{45-53}$

\section{Atomic charges}

In this part, all chemical interactions are either electrostatic (polar) or orbital (covalent), electric charges in the molecule are obviously responsible for electrostatic interactions. The charge distribution on the molecule has an important influence on the vibrational spectra. The negative atomic charge on $(\mathrm{N} 12, \mathrm{~N} 14)$ and $(\mathrm{N} 8, \mathrm{~N} 10)$ has increased considerably for phenyl groups (Table 2) for the compounds 2 and 4. The opposite was observed in amino groups of compounds 1 and 3 . As shown in Table 2, the carbon C5 and C19 have the highest positive charge $(+0.350)$ in the compound 2 (5-(3-chlorobenzo[b]thien-2-yl)-2(Nphenylamino)-1,3,4-thiadiazole) and compound 4 (5-[(2,4-dichlorophen-2(N-phenylamino)-1,3,4thiadiazole). These positions of C ATOMS with the highest positive charge lead to preferential sites of nucleophilic attack. 


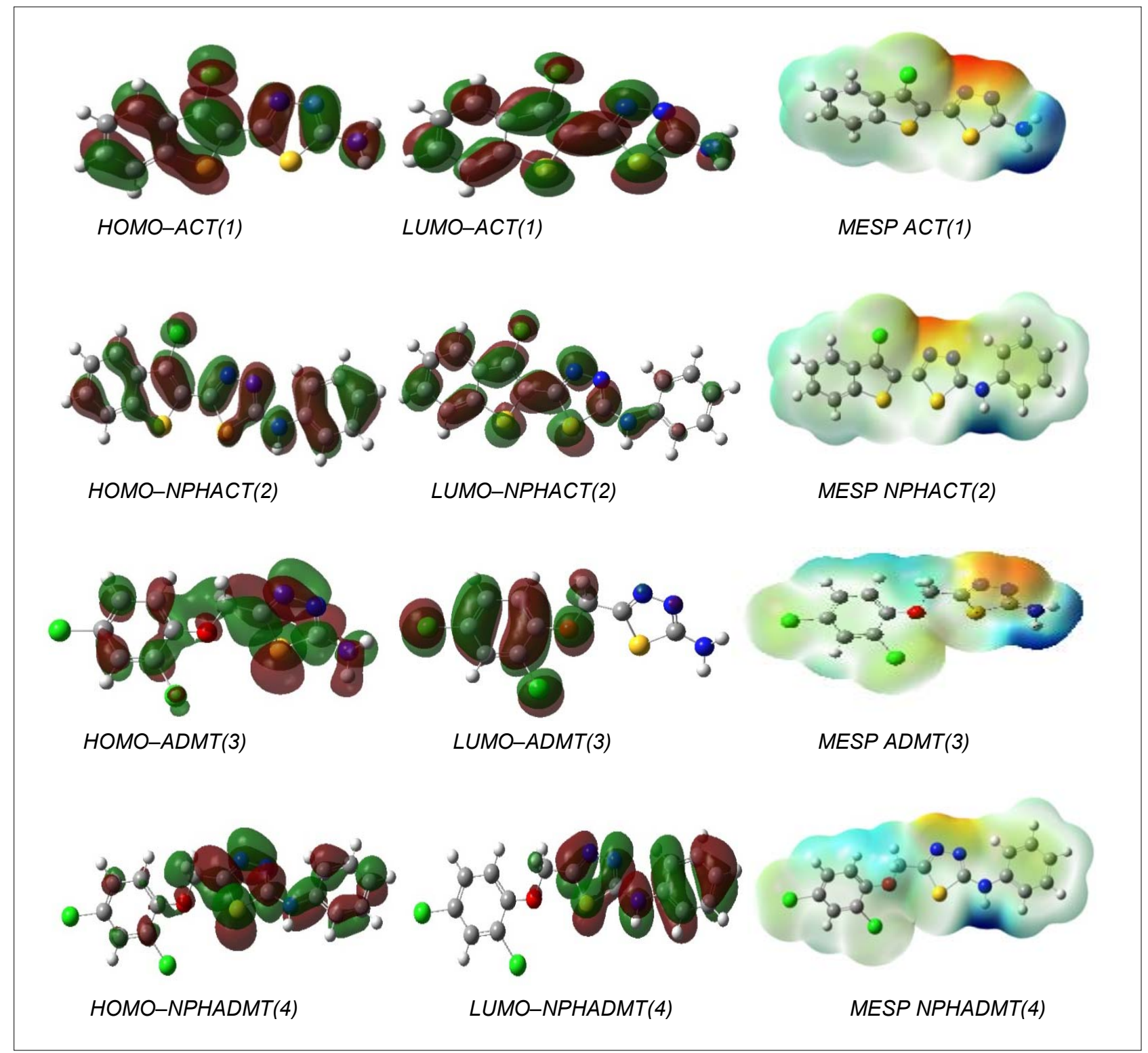

Fig. 2 - HOMO, LUMO and MESP surfaces of the studied molecules.

\section{2-amino-5-(3-chlorobenzo[b]thien-2-yl-1,3,4-} thiadiazole (1):

The optimized geometry of compound $\mathbf{1}$, which we obtained by DFT methods, yields almost planar structure. In this molecule, some of the carbon atoms have positive excess charge, and some other have negative excess charge, the magnitude of positive charges varies from +0.081 to +0.304 , whereas for the negative charges it varies from -0.179 to -0.085 . On the other hand all the nitrogen atoms have negative excess charge, which varies from -0.756 to -0.270 . On the contrary the sulfur atoms, possess positive excess charge, their magnitude varies from +0.204 to +0.258 . Finally, the chlorine atom has a positive charge of +0.050 .

\section{5-(3-chlorobenzo[b]thien-2-yl)-2-(N-phenyl-} amino)-1,3,4-thiadiazole (2): Similar to molecule 1, the optimized geometry of molecule 2 also yields an almost planar structure. The carbon atoms, in this compound possess positive and negative charges. The magnitude of positive charges varies from +0.145 to +0.369 , whereas for the negative charges it varies from -0.196 to -0.085 . On the other hand all the nitrogen atoms have negative excess charge; their magnitude varies from -0.753 to -0.259 . On the contrary the sulfur atoms, possess positive charges, their magnitude varies from +0.190 to +0.258 . Finally, the chlorine atom has a positive charge of +0.052 . 
Table 3

Calculated Mulliken Atomic Charge for compounds 1-4

\begin{tabular}{c|c|c|c|c|c|c|c}
\hline \multicolumn{2}{c|}{ Compound 1 } & \multicolumn{2}{c|}{ Compound 2 } & \multicolumn{2}{c|}{ Compound 3 } & \multicolumn{2}{c}{ Compound 4 } \\
\hline Atom Type & $\begin{array}{c}\text { Charge } \\
(\overline{\mathrm{e}})\end{array}$ & Atom Type & $\begin{array}{c}\text { Charge } \\
(\overline{\mathrm{e}})\end{array}$ & $\begin{array}{c}\text { Atom } \\
\text { Type }\end{array}$ & $\begin{array}{c}\text { Charge } \\
(\overline{\mathrm{e}})\end{array}$ & $\begin{array}{c}\text { Atom } \\
\text { Type }\end{array}$ & $\begin{array}{c}\text { Charge } \\
(\overline{\mathrm{e}})\end{array}$ \\
\hline $1 \mathrm{C}$ & +0.081 & $1 \mathrm{C}$ & +0.145 & $1 \mathrm{C}$ & +0.107 & $1 \mathrm{C}$ & -0.146 \\
$2 \mathrm{~S}$ & +0.204 & $2 \mathrm{C}$ & -0.127 & $2 \mathrm{~N}$ & -0.260 & $2 \mathrm{C}$ & -0.126 \\
$3 \mathrm{~N}$ & -0.270 & $3 \mathrm{C}$ & -0.168 & $3 \mathrm{~S}$ & +0.221 & $3 \mathrm{C}$ & -0.160 \\
$4 \mathrm{C}$ & +0.304 & $4 \mathrm{C}$ & -0.179 & $4 \mathrm{~N}$ & -0.305 & $4 \mathrm{C}$ & -0.133 \\
$5 \mathrm{~N}$ & -0.294 & $5 \mathrm{C}$ & -0.143 & $5 \mathrm{C}$ & +0.299 & $5 \mathrm{C}$ & +0.350 \\
$6 \mathrm{~N}$ & -0.756 & $6 \mathrm{C}$ & -0.116 & $6 \mathrm{C}$ & +0.401 & $6 \mathrm{C}$ & -0.196 \\
$7 \mathrm{C}$ & +0.145 & $7 \mathrm{C}$ & -0.085 & $7 \mathrm{C}$ & -0.131 & $7 \mathrm{C}$ & +0.108 \\
$8 \mathrm{C}$ & -0.128 & $8 \mathrm{C}$ & -0.189 & $8 \mathrm{C}$ & -0.186 & $8 \mathrm{~N}$ & -0.248 \\
$9 \mathrm{C}$ & -0.168 & $9 \mathrm{~S}$ & +0.258 & $9 \mathrm{C}$ & -0.136 & $9 \mathrm{~S}$ & +0.210 \\
$10 \mathrm{C}$ & -0.179 & $10 \mathrm{Cl}$ & +0.052 & $10 \mathrm{C}$ & -0.138 & $10 \mathrm{~N}$ & -0.332 \\
$11 \mathrm{C}$ & -0.143 & $11 \mathrm{C}$ & +0.085 & $11 \mathrm{C}$ & -0.064 & $11 \mathrm{C}$ & +0.360 \\
$12 \mathrm{C}$ & -0.116 & $12 \mathrm{~N}$ & -0.259 & $12 \mathrm{Cl}$ & -0.015 & $12 \mathrm{C}$ & -0.107 \\
$13 \mathrm{C}$ & -0.085 & $13 \mathrm{~S}$ & +0.190 & $13 \mathrm{Cl}$ & +0.013 & $13 \mathrm{C}$ & +0.401 \\
$14 \mathrm{C}$ & -0.186 & $14 \mathrm{~N}$ & -0.320 & $14 \mathrm{O}$ & -0.507 & $14 \mathrm{C}$ & -0.132 \\
$15 \mathrm{~S}$ & +0.258 & $15 \mathrm{C}$ & +0.369 & $15 \mathrm{C}$ & -0.107 & $15 \mathrm{C}$ & -0.186 \\
$16 \mathrm{Cl}$ & +0.050 & $16 \mathrm{C}$ & -0.133 & $16 \mathrm{~N}$ & -0.753 & $16 \mathrm{C}$ & -0.136 \\
- & - & $17 \mathrm{C}$ & -0.196 & - & - & $17 \mathrm{C}$ & -0.138 \\
- & - & $18 \mathrm{C}$ & -0.126 & - & - & $18 \mathrm{C}$ & -0.064 \\
- & - & $19 \mathrm{C}$ & +0.350 & - & - & $19 \mathrm{Cl}$ & +0.014 \\
- & - & $20 \mathrm{C}$ & -0.146 & - & - & $20 \mathrm{Cl}$ & -0.015 \\
- & - & $21 \mathrm{C}$ & -0.159 & - & - & $21 \mathrm{O}$ & -0.507 \\
- & - & $22 \mathrm{~N}$ & -0.753 & - & - & $22 \mathrm{~N}$ & -0.747 \\
& & & & & & & \\
\hline
\end{tabular}

\section{2-amino-5-[(2,4-dichlorophénoxy)methyl]-} 1,3,4-thiadiazole (3) For compound 3, the optimized geometry yields a non-planar structure. Similar to the two previous molecules (1 and 2) the carbon atoms in molecule $\mathbf{3}$, possess positive and negative charges. The magnitude of positive charges vary from +0.107 to +0.401 . However, for the negative charges it varies from -0.064 to -0.186. Although all nitrogen atoms possess negative charges their value varies from -0.753 to -0.250 . The oxygen atom has a negative charge of -0.507 . The sulfur atom has positive charge of +0.221 . Finally, for the chlorine atoms, one of them has a positive charge of +0.013 and the other one possesses a negative charge of -0.015 .

\section{5-[(2,4-dichlorophénoxy) phenylamino)-1,3,4-thiadiazole (4)}

For the molecule 4, the optimized geometry yields also a non-planar structure. Similar to the rest of compounds in this series the carbon atoms in compound 4 possess positive and negative charges. The magnitude of positive charges varies from +0.108 to +0.401 . However, the magnitude of negative charges varies from -0.064 to -0.196 . On the other hand all nitrogen atoms possess a negative charge, its value varies -0.747 to -0.248 . The oxygen atom has a negative charge of -0.507 . The sulfur atom has positive charge of +0.210 .
Finally, for the chlorine atoms, one of them possesses a positive charge of +0.014 , while the other one possesses a negative charge of -0.015 .

The large charge accumulation takes place on the carbon (C6H5-) and nitrogen atoms. These results show that phenyl group and nitrogen atoms have more negative excess charges in comparison with other atoms. This means that phenyl group and nitrogen atoms undergo protonation reaction with acidic reagents. We can conclude that the thiadiazole ring of $\mathbf{2}$ is more active than the thiadiazole ring of the other molecules in the series when it comes to a nucleophilic reaction, hence to the presence of phenyl group attached to thiadiazole ring of $\mathbf{2}$, which has the ability to donate more electrons.

\section{Vibrational spectral analysis}

Its experimental and theoretical FT-IR bands spectra are illustrated in (Fig. 3) their frequencies, alongside their activities, are listed in Table 4. Upon comparison, it is evident that there is very close agreement between the experimental wave numbers and those generated by the DFT method. Hence the vibrational modes are discussed under three heads: (I) $\mathrm{C}-\mathrm{H} / \mathrm{NH}$ vibrations (II) $\mathrm{NH}_{2}$ group vibrations (III) $\mathrm{C}=\mathrm{N}$ vibrations (IV) $\mathrm{C}=\mathrm{C}$ vibrations. The thiadiazole ring containing 3 hetero 
atoms (two nitrogens and sulfur) has vibrations corresponding to N-N, C-N and C-S stretching modes. $^{54}$

\section{(I)C-H/N-H vibrations}

The structure shows the presence of $\mathrm{C}-\mathrm{H}$ stretching vibrations in the region 3000-3300 $\mathrm{cm}^{-1}$, which is the characteristic region for ready identification of $\mathrm{C}-\mathrm{H}$ stretching vibrations. ${ }^{55}$ The peaks observed at $3017,3049,3090,3064 \mathrm{~cm}^{-1}$ are due to stretching vibrations. The $\mathrm{C}-\mathrm{H}$ stretching frequency of such compounds falls very nearly in the region of $3029-3200 \mathrm{~cm}^{-1}$ for asymmetric stretching and $3200-3236 \mathrm{~cm}^{-1}$ for symmetric stretching modes of vibration. The out-plane bending vibrations are established at $3213 \mathrm{~cm}^{-1}$ for NPHACT and $3189 \mathrm{~cm}^{-1}$ for NPHADMT by DFT method. The N-H stretching vibrations in primary amines generally occur in the region of 3500 $3300 \mathrm{~cm}^{-1} .{ }^{56-58}$ Primary amines examined in dilute solution display two weak absorption bands, one near $3500 \mathrm{~cm}^{-1}$ and the other near $3400 \mathrm{~cm}^{-1}$. These bands represent, respectively, the asymmetrical and symmetrical N-H stretching modes. ${ }^{59}$ The bands observed at $3214,3193 \mathrm{~cm}^{-1}$ was assigned to the N-H stretching vibration of NPHACT and NPHADMT, which are in good agreement with computed vibrations by B3LYP/6-31G (d) method at $3623 \mathrm{~cm}^{-1} 1$ for the two compounds.

\section{(II) $\mathrm{NH}_{2}$ vibrations}

The $\mathrm{NH}_{2}$ group gives rise to six internal modes of vibrations viz., the symmetric stretching, the antisymmetric stretching, the symmetric deformation or the scissoring, the rocking, the wagging and torsional modes. The $\mathrm{NH}_{2}$ group has two $\mathrm{NH}$ stretching vibrations, one being anti-symmetric and the other symmetric. The frequency of asymmetric vibration is higher than that of symmetric one. In the case of two $\mathrm{NH}$ bonds of the $\mathrm{NH}_{2}$ group being identical, the mas and ms modes satisfy the relationship $\mathrm{ms}=345.5+0.876$ mas as proposed empirically by Ballamy and Williams,${ }^{60}$ where mas and $\mathrm{ms}$ are in wave numbers. For ADMT, the two $\mathrm{NH}_{2}$ stretching modes appear at $3433-3200 \mathrm{~cm}^{-1}$ and $3310 \mathrm{~cm}^{-1}$ for ACT in the infrared spectrum. The lower frequency is assigned to the symmetric (ms) and the higher one to the anti-symmetric (mas) mode. Using the relation of Bellamy and Williams and taking mas to be $3310 \mathrm{~cm}^{-1}$, ms comes out to be $3200 \mathrm{~cm}^{-1}$ which is $53 \mathrm{~cm}^{-1}$ lower than the observed frequency $\left(3253 \mathrm{~cm}^{-1}\right)$.

The theoretically scaled down value at $1631 \mathrm{~cm}^{-1}$ assigned to $\mathrm{NH}_{2}$ scissoring vibrations are well within the region. ${ }^{61}$ The frequency in the FT-IR spectrum at $3555 \mathrm{~cm}^{-1}$ for ACT and $3557 \mathrm{~cm}^{-1}$ for ADMT are assigned to $\mathrm{NH}_{2}$ rocking vibration.

\section{(III) $\mathrm{C}=\mathrm{N}$ vibrations}

Computed values are at $654 / 911 \mathrm{~cm}^{-1}$ in B3LYP are assigned to C-S stretching mode, which are well matched with weak band at $798 \mathrm{~cm}^{-1}$ in FTIR spectrum. Difficult task of identifying $\mathrm{C}=\mathrm{N}$ vibrations due to the mixing of several bands is made somewhat simpler by molecular simulation programs and normal mode analysis. Atalay et $a l .{ }^{62}$ have assigned $\mathrm{C}=\mathrm{N}$ stretching vibrations at 1634 and $1610 \mathrm{~cm}^{-1}$ in IR spectrum of ACT, NPHACT and 1660, $1637 \mathrm{~cm}^{-1}$ of ADMT, NPHADMT. The modes calculated at 1539 and1594 $\mathrm{cm}^{-1}$ of ACT, NPH-ACT; 1671 and $1586 \mathrm{~cm}^{-1}$ of ADMT, NPHADMT are the $\mathrm{C}=\mathrm{N}$ stretching modes which are in good agreement with experimental values. It is a mixed mode having contribution from $\mathrm{C}-\mathrm{C}$ stretch and $\mathrm{C}-\mathrm{H}$ bending vibrations. The in-plane C-S-C and N-C-S vibrations are also well matched with the experimental values.

\section{$(\mathrm{IV}) \mathrm{C}=\mathrm{C}$ vibrations}

The ring stretching vibrations are very much important in the spectrum of aromatic compounds and are highly characteristic of the aromatic ring itself. However, empirical assignments of vibrational modes for peaks in the finger print region are difficult. Bands between 1400 and 1650 $\mathrm{cm}^{-1}$ in benzene derivatives are assigned to these modes. In general, the bands are of variable intensity and observed at 1625-1590, 1590-1575, $1540-1470,1460-1430$ and $1380-1280 \mathrm{~cm}^{-1}$ from the frequency ranges given by Varsanyi ${ }^{63}$ for the five bands in the finger print region. In the 134thiadiazole derivatives, the bands width are of different intensity and observed at 1598, 1582, 1557 and $1565 \mathrm{~cm}^{-1}$ in FT-IR have been assigned to $\mathrm{C}=\mathrm{C}$ stretching vibrations. The theoretically calculated values at $1619,1573,1572$ and $1535 \mathrm{~cm}^{-1}$ agrees well with the experimental values. 


\section{${ }^{1}$ H NMR analysis}

Chemical shifts are recognized as an imperative part of the information contained in NMR spectra. Both experimental and theoretical NMR chemical shifts are used to identify the organic compounds. GIAO (Gauge Independent Atomic Orbital) method exhibits a faster convergence of the calculated properties upon extension of the basis set used compared with other methods. GIAO approach is one of the most common methods for calculating isotropic nuclear magnetic shielding tensors. In GIAO method, the atomic basis functions depend explicitly on the magnetic field. ${ }^{1} \mathrm{H}$ NMR chemical shifts of 1,3,4-thiadiazolederivatives are calculated with GIAO procedure using DFT/B3LYP/6-31G(d) method and using Tetramethylsilane (TMS) as reference. $^{65-68}$

The NMR spectra calculations were carried out by Gaussian 09 package. The experimental and theoretical ${ }^{1} \mathrm{H}$ NMR spectra are shown in Table 5. The calculated ${ }^{1} \mathrm{H}$ NMR showed a good agreement with the experimental results obtained for the new 1,3,4-thidiazole derivatives. The obtained theoretical results were helpful for the detailed assignments of experimental ${ }^{1} \mathrm{H}$ NMR spectra of the studied compound. Quantum chemical calculations were used for a better understanding of the NMR properties as well as for an analysis of the geometrical parameters in this novel compound. The $\mathrm{H}$ atom is the smallest of all atoms and mostly localized on the periphery of molecules; therefore their chemical shifts would be more susceptible to intermolecular interactions in the aqueous solutions as compared to that for other heavier atoms. Hydrogen attached or nearby electron-withdrawing atom can decrease the shielding and move the resonance of attached proton towards a higher frequency, whereas electron-donating atom or group increases the shielding and moves the resonance towards a lower frequency. ${ }^{69}$ A singlet signal at 11.00 (Calculated at 7.10-9.04) ppm due to protons of N-H group for (NPHACT), a multiplet signal in the range 7.31-7.57 (Calculated at 10.13-10.79) ppm due to eight aromatic protons of phenyl rings for (NPHADMT), a singlet signal at 7.27(Calculated at 19.64) $\mathrm{ppm}$ due to proton of $(\mathrm{O}-\mathrm{CH} 2)$, and singlet signal at 5.48 (Calculated at 13.51) ppm due to proton of $(\mathrm{N}-\mathrm{H})$. The theoretical ${ }^{1} \mathrm{H}$ NMR chemical shifts showed an acceptable agreement with experimental ones (Fig. 5-8).

Table 4

Comparison of experimental infrared wave numbers $\left(\mathrm{cm}^{-1}\right)$ with theoretical harmonic frequencies $\left(\mathrm{cm}^{-1}\right)$, infrared intensities, of molecule ACT, NPHACT, ADMT and NPHADMT

\begin{tabular}{|c|c|c|c|c|}
\hline \multirow[t]{2}{*}{ Molecules } & \multirow[t]{2}{*}{ Assignments } & \multirow{2}{*}{$\begin{array}{l}\text { Experimental } \\
\text { Frequency in } \\
\left(\mathrm{cm}^{-1}\right)^{1} \text { Ref. }^{74}\end{array}$} & \multicolumn{2}{|c|}{ Calculated frequencies } \\
\hline & & & Freq $\left(\mathrm{cm}^{-1}\right)$ & Intensity $(\mathrm{km} / \mathrm{mol})$ \\
\hline $\mathrm{ACT}, 1$ & $\begin{array}{c}v(\mathrm{C}=\mathrm{C})_{\text {aro }} \\
v(\mathrm{C}=\mathrm{N}) \text { sym } \\
v(\mathrm{C}-\mathrm{H}) \text { asy } \\
v(\mathrm{~N}-\mathrm{H} 2)\end{array}$ & $\begin{array}{l}1565 \\
1634 \\
3017 \\
3310\end{array}$ & $\begin{array}{l}1573 \\
1539 \\
3213 \\
3555\end{array}$ & $\begin{array}{c}64.998 \\
345.948 \\
20.523 \\
83.470\end{array}$ \\
\hline NPHACT, 2 & $\begin{array}{l}v(\mathrm{C}=\mathrm{C})_{\text {aro }} \\
v(\mathrm{C}=\mathrm{N}) \text { sym } \\
v(\mathrm{C}-\mathrm{H}) \text { asy } \\
v(\mathrm{~N}-\mathrm{H})\end{array}$ & $\begin{array}{l}1598 \\
1610 \\
3049 \\
3214\end{array}$ & $\begin{array}{l}1572 \\
1594 \\
3213 \\
3623\end{array}$ & $\begin{array}{c}154.248 \\
649.283 \\
4.646 \\
54.460\end{array}$ \\
\hline ADMT, 3 & $\begin{array}{c}\gamma(\mathrm{C}=\mathrm{C})_{\text {aro }} \\
v(\mathrm{C}=\mathrm{N}) \text { sym } \\
v(\mathrm{C}-\mathrm{H}) \\
v(\mathrm{C}-\mathrm{H}) \text { asy } \\
v(\mathrm{~N}-\mathrm{H} 2)\end{array}$ & $\begin{array}{c}1582 \\
1660 \\
2977 \\
3090 \\
3200-3433\end{array}$ & $\begin{array}{l}1535 \\
1671 \\
3021 \\
3222 \\
1217\end{array}$ & $\begin{array}{c}106.312 \\
161.492 \\
20.793 \\
5.483 \\
49.042\end{array}$ \\
\hline NPHADMT, 4 & $\begin{array}{c}v(\mathrm{C}=\mathrm{C})_{\text {aro }} \\
v(\mathrm{C}=\mathrm{N}) \text { sym } \\
v(\mathrm{C}-\mathrm{H}) \text { asy } \\
v(\mathrm{C}-\mathrm{H}) \text { asy } \\
v(\mathrm{~N}-\mathrm{H})\end{array}$ & $\begin{array}{c}1557 \\
1637 \\
3019 \\
3064 \\
3193-3266\end{array}$ & $\begin{array}{l}1619 \\
1586 \\
3020 \\
3189 \\
3623\end{array}$ & $\begin{array}{c}8.587 \\
12.960 \\
20.830 \\
25.702 \\
38.127\end{array}$ \\
\hline
\end{tabular}

v: stretching; $\gamma$ : out of plane bending; aro: aromatic; sym: symmetrical; asy: symmetric 


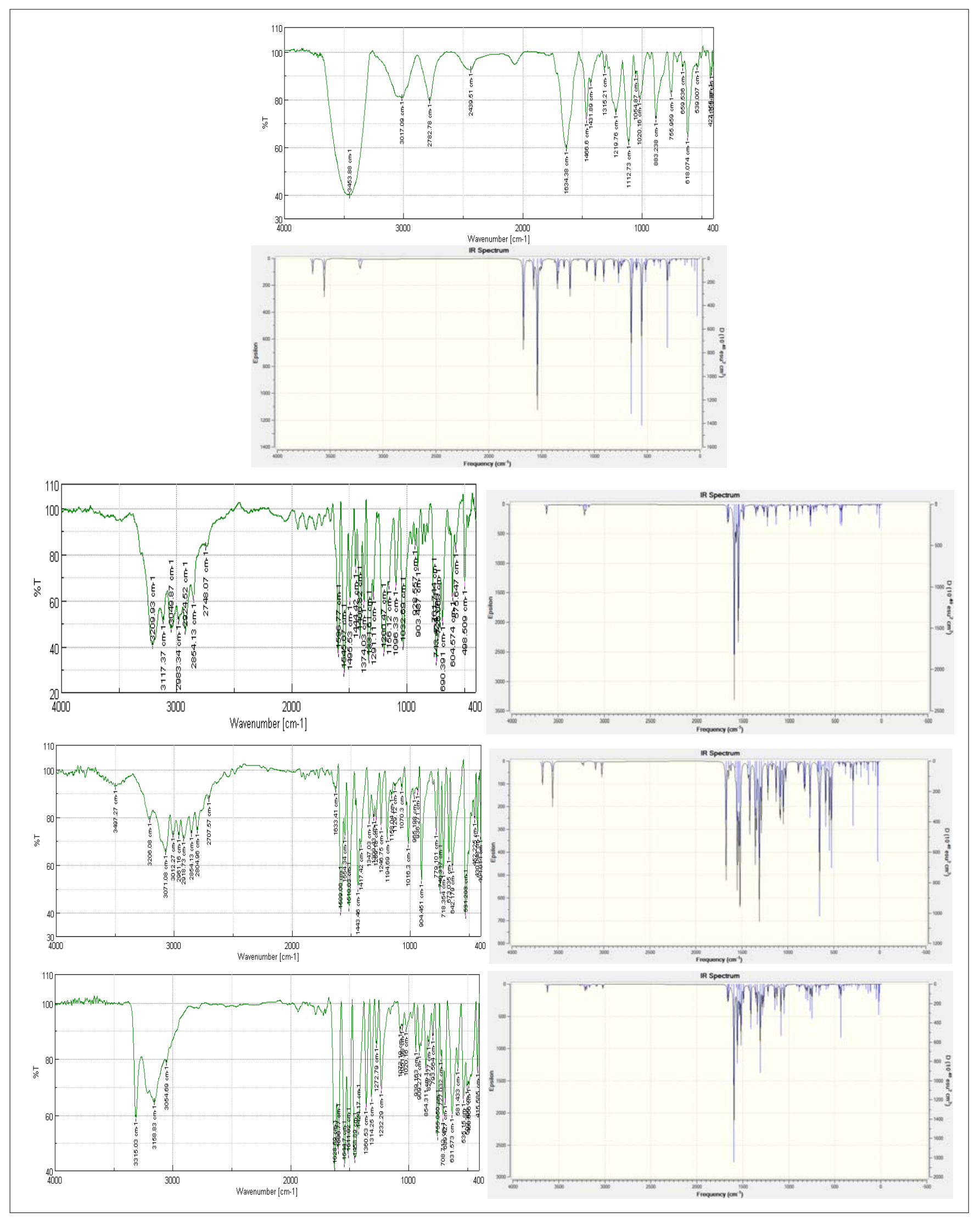

Fig. 3 - Experimental (a) and theoretical (b) B3LYP level FT-IR spectra of compounds 1,2,3 and 4. 


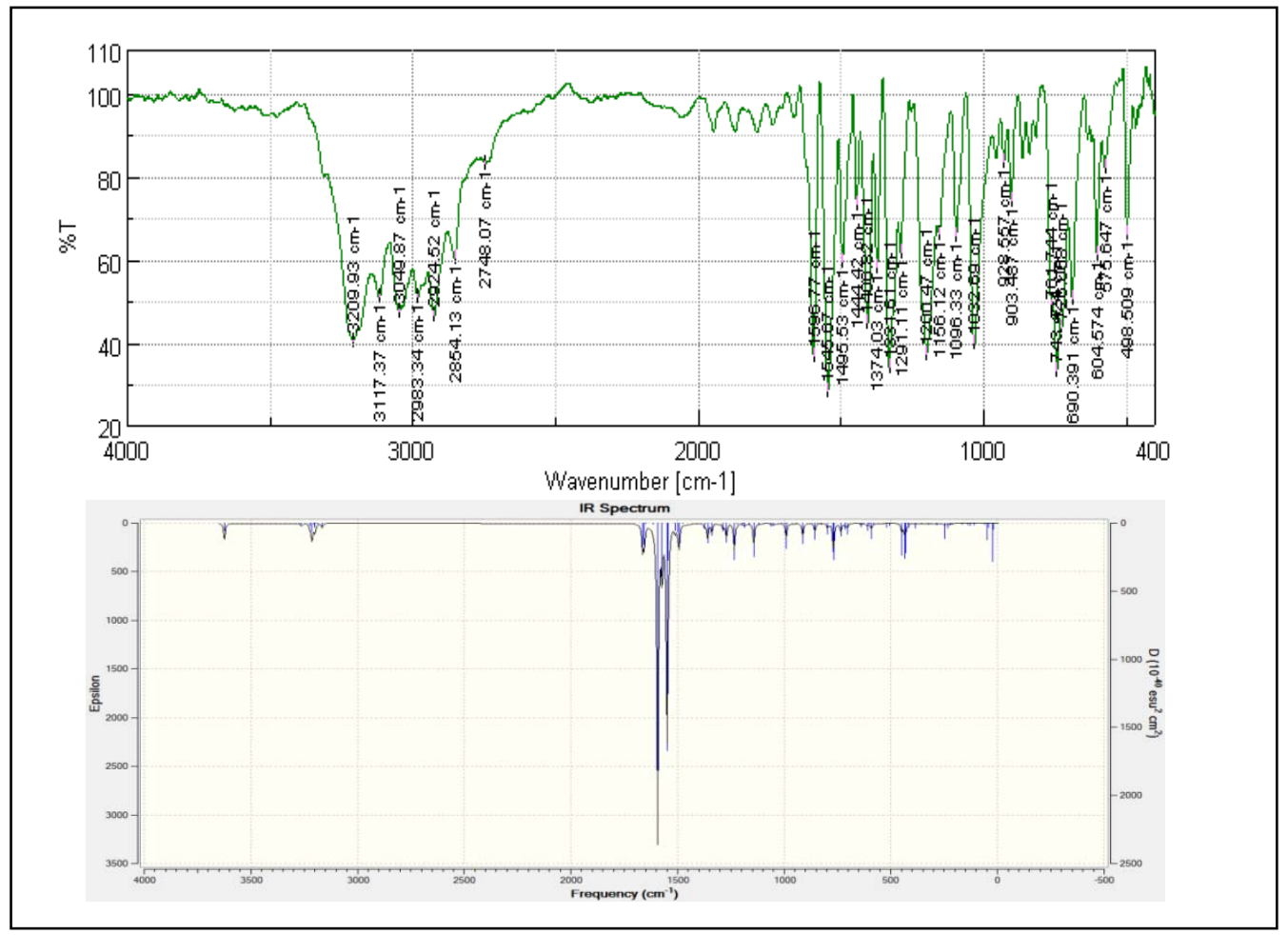

Fig. 4 - Experimental (a) and theoretical (b) B3LYP level FT-IR spectra of compound 2.

Table 5

${ }^{1} \mathrm{H}-\mathrm{NMR}$ Chemical shift (ppm) for different Compounds 1.2.3.4

\begin{tabular}{c|c|c|c|c}
${ }^{\mathbf{1}}$ H-NMRtheo(ppm) & \multicolumn{1}{c}{$\begin{array}{c}\text { NPHADMT } \\
\text { (4) }\end{array}$} \\
\hline $\begin{array}{c}\text { C.N } \\
\text { Atoms }\end{array}$ & $\begin{array}{c}\text { ACT } \\
\mathbf{( 1 )}\end{array}$ & $\begin{array}{c}\text { NPHACT } \\
\mathbf{( 2 )}\end{array}$ & $\begin{array}{c}\text { ADMT } \\
\mathbf{( 3 )}\end{array}$ & - \\
$17 \mathrm{H}$ & 4.732 & - & 9.510 & - \\
$18 \mathrm{H}$ & 4.622 & - & 9.294 & - \\
$19 \mathrm{H}$ & 7.766 & - & 9.360 & - \\
$20 \mathrm{H}$ & 7.483 & - & 8.336 & - \\
$21 \mathrm{H}$ & 7.574 & - & 7.505 & 10.799 \\
$22 \mathrm{H}$ & 7.574 & - & 8.485 & 10.295 \\
$23 \mathrm{H}$ & - & 8.261 & 8.288 & 19.840 \\
$24 \mathrm{H}$ & - & 8.083 & - & 19.666 \\
$25 \mathrm{H}$ & - & 7.954 & - & 10.665 \\
$26 \mathrm{H}$ & - & 7.931 & - & 10.135 \\
$27 \mathrm{H}$ & - & 7.772 & - & 19.666 \\
$28 \mathrm{H}$ & - & 7.489 & - & 19.645 \\
$29 \mathrm{H}$ & - & 7.840 & - & 10.614 \\
$30 \mathrm{H}$ & - & 9.040 & - & 10.237 \\
$31 \mathrm{H}$ & - & 6.784 & - & 13.510 \\
$32 \mathrm{H}$ & - & - & - & \\
$33 \mathrm{H}$ & - & &
\end{tabular}

\section{Study of chemical reactivities}

To explain the chemical reactivity of the studied compounds, several electronic parameters were used, such as hardness index, chemical potential, softness, electronegativity and electrophilicity. ${ }^{70-72}$

The results show that molecular stability depends on hardness. Pauling introduced electronegativity as a force from one atom to the other to maintain and capture its electrons. Equations 1 to 3 show hardness $(\eta)$, chemical potential $(\mu)$, and electronegativity $(X)$ formula, respectively.

$$
\begin{gathered}
\eta=\frac{1}{2}\left(\frac{\partial 2 E}{\partial N 2}\right) v(r)=\frac{1}{2}\left(\frac{\partial 2 \mu}{\partial N}\right) v(r) \\
v(r)=\left[\frac{\partial E}{\partial N}\right] \mu \\
X=-\mu=-\left[\frac{\partial E}{\partial N}\right] v(r)
\end{gathered}
$$


Table 6

Computed electronegativity $(X)$, hardness $(\eta)$, softness (Ş) in electron volt $(\mathrm{eV})$

\begin{tabular}{l|c|c|c|c}
\hline & $\begin{array}{c}\text { ACT } \\
\text { (1) }\end{array}$ & $\begin{array}{c}\text { NPHACT } \\
\text { (2) }\end{array}$ & $\begin{array}{c}\text { ADMT } \\
\mathbf{( 3 )}\end{array}$ & $\begin{array}{c}\text { NPHADMT } \\
\mathbf{( 4 )}\end{array}$ \\
\hline $\mathbf{A}$ & 1.773 & 1.846 & 0.929 & 1.089 \\
$\mathbf{I}$ & 5.825 & 5.589 & 6.353 & 5.835 \\
$\boldsymbol{\mu}$ & -3.799 & -3.717 & -3.641 & -3.462 \\
$\mathbf{\eta}$ & 2.025 & 1.871 & 2.712 & 2.372 \\
$\mathbf{S}$ & 0.493 & 0.534 & 0.368 & 0.421 \\
$\boldsymbol{\omega}$ & 3.563 & 3.692 & 2.444 & 2.526 \\
\hline
\end{tabular}

Parr et al. investigated electrophilicity as a measurement unit for decreasing energy that considered the maximum of electrons exchanged between electron donor and electron acceptor. ${ }^{73-75}$ They defined electrophilicity in the following equation:

$$
\omega=\mu^{2} / 2 \eta
$$

If one of two molecules reacting together acts as an electrophile, that molecule has larger electrophilicity index (electron acceptor). This new reactivity index measures the stability of energy when it captures an extra electron charge $(\Delta N)$ from surrounding. Electrophilicity is a reactivity descriptor that accepts some natural Electrophilicity in relative scale. Recently, it's proven that this quantity can be used to assess the toxicity of various pollutants based on their reactivity and selected place. ${ }^{73,74,76,77}$ The frontier orbital gap helps characterize the chemical reactivity and kinetic stability of the molecule. A molecule with a small frontier orbital gap is more polarizable and is generally associated with a high chemical reactivity, low kinetic stability and is also termed as soft molecule. For understanding various aspects of pharmacological sciences including drug design and the possible eco-toxicological characteristics of the drug molecules, several new chemical reactivity descriptors have been proposed.

Conceptual DFT based descriptors have helped in many ways to understand the structure of the molecules and their reactivity by calculating the chemical potential, global hardness and electrophilicity. Using HOMO and LUMO orbital energies, the ionization energy and electron affinity can be expressed ${ }^{78}$ as:

$$
\begin{gathered}
\mathrm{I}=-\mathrm{E}_{\text {Hомо }}, \mathrm{A}=-\mathrm{E}_{\mathrm{LUMO}} \\
\eta=\left(-\mathrm{E}_{\mathrm{HOMO}}+\mathrm{E}_{\mathrm{LUMO}}\right) / 2 \\
\mu=\left(\mathrm{E}_{\mathrm{HOMO}}+\mathrm{E}_{\mathrm{LUMO}}\right) / 2
\end{gathered}
$$

Where I and A are the first ionization potential and electron affinity of the chemical species. ${ }^{78}$ The calculated values of 1,3,4-thiadiazole derivatives are given in Table 6.

According to the computed results in Table 6, compound 2 (5- (3-chlorobenzo [b] thien-2-yl) -2(N-phenylamino) -1,3,4-thiadiazole) has smaller ionization energy (I) $(5.59 \mathrm{eV})$ and higher electron affinity (A) $(1.85 \mathrm{eV})$ compared to the rest of the series, thus, as we mentioned before this compound is the most active, also it has the smallest global hardness $(\eta)(1.87 \mathrm{eV})$, highest global softness (Ş) $(0.53 \mathrm{eV})$, and highest global electrophilicity index $(\omega)(3.67 \mathrm{eV})$ in the series, thus, compound 2 is a stronger electrophile compared to the other studied compounds. And we can see that all values of chemical potential of all compounds are negative which means that these compounds are stable.

The moderate value of chemical potential $(-3.72 \mathrm{eV})$ and the high value of electrophilicity index $(3.69 \mathrm{eV})$ for compound 2 favor its electrophilic behavior. On the other hand, the high value of chemical potential $(-3.64 \mathrm{eV})$ and the low value of electrophilicity index $(2.44 \mathrm{eV})$ for compound 3 favor its nucleophilic behavior.

\section{CONCLUSION}

We chose a series of 1,3,4-thiadiazole derivatives after bi it has been concluded that compounds 2-amino-5(3-chlorobenzo[b]thien-2-yl1,3,4-thiadiazole(ACT); 5-(3-chlorobenzo[b]thien2-yl)-2(N-phenylamino)-1,3,4-thiadiazole(NPHACT); 2-amino-5-[(2,4-dichlorophenoxy)methyl]-1,3,4thiadiazole(ADMT); 5-[(2,4-dichlorophenoxy)methyl ]5-[(2,4-dichlorophen-2(N-phenylamino)-1,3,4-thiadiazole (NPHADMT) were chosen to be studied by DFT method. Compound 2 would show higher chemical reactivity and stability than other from the values of their band gaps energy differences, total energies and dipole moments. Moreover, the Mulliken charges obtained allows a good understanding of the atomic theory and lowering of 
HOMO-LUMO band gap supports bioactive property of the molecule. In addition, ${ }^{1 \mathrm{H}} \mathrm{NMR}$ was calculated by using the gauge independent atomic orbital (GIAO)/solvent (DMSO) method and their spectra were simulated; the chemical shifts related to TMS were compared with experimental data, showing overall acceptable results.

In this Study we performed several DFT calculations on a series of 1,3,4-thiadiazole derivatives to investigate some of their properties and provide a direct comparison of experimental and computed Data, Compound 2 was found to be more chemically active than the rest of compounds in this series, according to their total energies as well as the HOMO-LUMO energy gaps. Moreover, the Mulliken charges obtained allows a good understanding of the atomic theory. In addition, ${ }^{1} \mathrm{H}$ NMR were calculated by using the gauge independent atomic orbital (GIAO)/solvent (DMSO) method to simulate their spectra providing us with a reasonable comparison with the observed results; also the chemical shifts related to TMS were compared with experimental data, showing an overall acceptable results.

\section{REFERENCES}

1. U. Kalidhar and A. Kaur, Res. J. Pharm. Biol. Chem. Sci., 2011, 2, 1091.

2. A. K. Singh, G. Mishra and K. Jyoti, J. Appl. Pharm. Sci., 2011, 01, 44.

3. N. Siddiqui, P. Ahuja, W. Ahsan, S. N. Pandeyaand S. Alam, J. Chem. Pharm. Res., 2009, 1, 19.

4. H. Bhuva, D. Sahua, B. Shah, D. Modi and M. Patel, Eur. J. Pharmacol., 2011,1, 528.

5. H. Ameen and A. Qasir, Iraqi. J. Pharm. Sci., 2012, 21, 98.

6. N. Kushwaha, S. Kushwaha and A. K. Rai, Int. J. Chem. Res., 2012, 4, 517.

7. G. Mishra, A. Singh and K. Jyoti, Int. J. Chem. Res., 2011, 3, 1380.

8. A. T. El. Sayed and A. M. El-Kazak, Chem. Eur. J., 2010, 1,6 .

9. J. K. Gupta, R. Dudhey and P. K. Sharma, J. Med. Chem., 2010, 1,1 .

10. S. Jalhan, A. Jindal, A. Gupta and J. Hemra, Asian J. Pharm. Clin. Res., 2012, 5, 199.

11. S. Jazayeri, M. H. Moshafi, L. Firoozpour, S. Emami, S. Rajabalian, M. Haddad, F. Pahlavanzadeh, M. Esnaashari, A. Shafiee and A. Foroumadi, Eur. J. Med. Chem., 2009, 44, 1205.

12. V. Padmavathi, G. Sudhakar, A. Padmaja, P. Kondaiah and A. Shazia, Eur. J. Med. Chem., 2009, 44, 2106.

13. N. Siddiqui and M. S. Alam, Biosci. Biotechnol. Res. Asia, 2009, 6, 261.

14. A. Dhakad, M. C. Sharma, S. C. Chaturvedi and S. Sharma, Dig. J. Nanomater. Biostruct., 2009, 4, 275.

15. F. Poorrajab, S. K. Ardestani, S. Emani, M. BehrouziFardmoghadam, A. Shafieeand and A. Foroumadi, Eur. J. Med. Chem., 2009, 44, 1758.
16. A. K. Gadad, M. B. Palkar, K. Anand, M. N. Noolvi, T. S. Boreddy and J. Wagwade, Bioorg. Med. Chem., 2008, 16, 276.

17. P. Kamotra, A. Gupta and R. Gupta, Indian J. Chem. B, 2007, 46, 980.

18. B. Sharma, A. Verma, S. Prajapatiand U. K. Sharma, Int. J. Med. Chem., 2013, 16, 2013.

19. B. Ahamad and M. Yusuf, Indian J. Chem. B, 2010, 49, 241.

20. K. B. Zheng, J. He and J. Zhang, Chin. Chem .Lett., 2008, 19, 1281.

21. R. Yadav, D. Yadav and S. K. Paliwal, Int. J. Pharm.,2012, 2, 1 .

22. A. Pandey, D. Dewangan, S. Verma, A. Mishra and R. Dubey, Int. J. Chem. Tech. Res., 2011, 3, 178.

23. HyperChem (Molecular Modeling System) Hypercube, MC, 1115 MV 4th Street, Gainesville, EL 32601; USA, http://www.hyperchem.com/.,2007.

24. Gaussian 09, M. J. Frisch, G. W. Trucks, H. B. Schlegel, G. E. Scuseria, M. A. Robb, J. R. Cheeseman, G. Scalmani, V. Barone, B. Mennucci, G. A. Petersson, H. Nakatsuji, M. Caricato, X. Li, H. P. Hratchian, A. F. Izmaylov, J. Bloino, G. Zheng, J. L. Sonnenberg, M. Hada, M. Ehara, K. Toyota, R. Fukuda, J. Hasegawa, M. Ishida, T. Nakajima, Y. Honda, O. Kitao, H. Nakai, T. Vreven, J. A.Montgomery, J. E. Peralta, F. Ogliaro, M. Bearpark, J. J. Heyd, E. Brothers, K. N. Kudin, V. N. Staroverov, T. Keith, R. Kobayashi, J. Normand, K. Raghavachari, A. Rendell, J. C. Burant, S. S. Iyengar, J. Tomasi, M. Cossi, N. Rega, J. M. Millam, M. Klene, J. E. Knox,J. B. Cross, V. Bakken, C. Adamo, J. Jaramillo, R. Gomperts, R. E. Stratmann, O. Yazyev, A. J. Austin, R. Cammi, C. Pomelli, J. W. Ochterski, R. L. Martin, K. Morokuma, V. G. Zakrzewski, G. A. Voth, P. Salvador, J. J. Dannenberg, S. Dapprich, A. D. Daniels, O. Farkas, J. B. Foresman, J. V. Ortiz, J. Cioslowski and D. J. Fox, Gaussian Inc., Wallingford, CT, 2010.

25. S. J. Vosko, L.Wilk and M. Nusair, Can. J. Phys., 1980, $58,1200$.

26. A. D. Becke, J. Chem. Phys., 1993, 98, 5648.

27. A. D. Becke, Phys. Rev., 1988, 38, 3098.

28. R. Ditchfield, W. J. Hehre and J. A. Pople, J. Chem. Phys., 1971, 54,724.

29. M. Karabacak, L. Sinha, O. Prasad, A. M. Asiri, M. Cinar, Spectrochim. Acta, Part A, 2013, 115, 753.

30. B. Abhisek, D. Apoorva, P. Subodh, A. Pande and V. Narayan, IJETT., 2013, 6, 3.

31. R. K. Srivastava, V. Narayan, A. Kumar, O. Prasad and L. Sinha, Res. J. Recent.Sci., 2012, $1,11$.

32. M. J. Frisch, J. A. Pople and J. S. Binkley, J. Chem. Phys., 1984, 80, 3265-3269.

33. R. Ditchfield, Mol. Phys., 1974, 27, 789.

34. K. Fukui, Angew. Chem., Int. Ed. Engl., 1982, 21, 801.

35. K. Dermeche, N. Tchouar, S. Belaidi and T. Salah, J. Bionanosci., 2015, 9, 395 .

36. G. L. Miesslerand D. A. Tarr, "Inorganic Chemistry", 2nd edition., Prentice-Hall Upper Saddle River, New Jersey, USA., 1999.

37. S. Erkoc and F. Erkoc, J. Mol. Struct: Theochem., 2005, 1,719 .

38. L. B. Kier, "Molecular Orbital Theory in Drug Research", Academic Press, New York, USA, 1981.

39. Z. Almi, S. Belaidi, N. Melkemi, S. Boughdiri and L. Belkhiri, Quantum Matter, 2016, 4, 124.

40. O. Oukil, N.Tchouar, S.Belaidi, T.Salah and M. Cinard, Rev. Roum.Chim., 2017, 62, 81-92. 
41. O. Prasad, L. Sinhaand and N. Kumar, J. At. Mol. Sci., 2010, 1, 201.

42. A. Chunzhi, C. Y. Li, W. Yonghua, C. Yadongand Y. Ling, Bioorg. Med. Chem. Lett., 2009, 19, 803.

43. K. S. Rajesh and V. Narayan, J. Chem. Pharm. Res., 2012, 4, 3287

44. J. S. Murray and K. Sen, "Molecular Electrostatic Potentials, Concepts and Applications", Elsevier, Amsterdam., 1996.

45. T. Salah, S. Belaidi, N. Melkemi and N. Tchouar, Rev. Theor. Sci., '2014, 3, 355.

46. S. Belaidi, Z. Almi, and D. Bouzidi, J. Comput. Theor. Nanosci., 2014, 11, 1 .

47. G. L. Miessler and D. A. Tarr, J. Inorg. Chem., 1999, 181.

48. L. Bouchlaleg, S. Belaidi, T. Salah and A. M. Alafeefy, $J$. Comput.Theor.Nanosci., 2015, 12, 3949.

49. K. J. Miller, J. Am. Chem. Soc., 1990, 112, 8533.

50. N. Prabavathi and A. Nilufer, J. Environ. Nanotechnol., 2014, 3, 130.

51. M. Karnan, V. Balachandran and M. Murugan, Spectrochim. Acta, Part A, 2012, 96, 51 .

52. A. Kerassa, S. Belaidi, D. Harkati, T. Lanez, L. Sinha and O. Prasad, Rev. Theor. Sci., 2015, $3,1$.

53. J. Pathak and L. Sinha, J. At. Mol. Sci., 2012, 3, 95.

54. P. Gautam, O. Prakash, R. K. Dani, N. K. Singh and R. K. Singh, Spectrochim. Acta Part A, 2014, 132, 278.

55. G. Socrates, "Infrared, Raman Characteristic Group Frequencies", third edition, John Wiley \& Sons Ltd., Chichester, 2001.

56. A. Altun, K. Golcuk and M. Kumru, J. Mol. Struct. (Theochem), 2003, 637, 155.

57. Y. Wang, S. Saebo and C. V. Pittman, J. Mol. Struct (Theochem), 1993, 281, 91.

58. N. Puviarasan, V. Arjunan and S. Mohan, Turk. J. Chem., 2002, 26, 323.

59. L. J. Bellamy and R. L. Williams, Spectrochim. Acta Part $A, \mathbf{1 9 5 7}, 9,341$.

60. J. Swaminathan, M. Ramalingam and N. Sundaraganesan, Spectrochim. Acta Part A, 2009, 71, 1776.
61. R. Saxena, L. D. Kauedpal and G. N. Mathur, J. Polym. Sci. Pol.Chem., 2002, 40, 3559.

62. Y. Atalay, F. Yakuphanoglu, M. Sekerci, D. Avc1 and A. Basoglu, Spectrochim. Acta Part A, 2006, 64, 68.

63. S. Subashchandrabose, A. R. Krishnan, H. Saleem, R. Parameswaria, N. Sundaraganesan, V. Thanikachalam and G. Manikandan, Spectrochim. Acta Part A, 2010, 77, 877.

64. N. Aoumeur, "Synthesis of penta-atomic nitrogencontaining heterocycles from hydrazine derivatives. Biological Application", Thesis of magister, 2011, University of USTO, Oran.

65. Z. A. Saleh, F. W. Askar and S. M. A. Ridha, Int. J. Mater. Chem., 2015, 5, 31.

66. H. F. Hameka, Mol. Phys., 1959, 2, 64.

67. R. Ditchfield, Mol. Phys., 1974, 27, 789.

68. K. Wolinsky, J. F. Hinton and P. Pulay, J. Am. Chem. Soc., 1990, 112, 8251.

69. Subramanian, N. Sundaraganesan and J. Jayabharathi, Spectrochim. Acta Part A, 2010, 76, 259.

70. R. G Parr and W. Yang, Annu. Rev.Phys.Chem., 1995, $46,701$.

71. J. Garza and J. Robles, Density-Functional-Theory Softness Kernel.Physical .Rev. A, 1993, 47, 2680.

72. A. Lozovoi, A. Alavi, J. Kohanoff and R. Lynden-Bell, J. Chem. Phys., 2001, 115, 1661.

73. H. Lu and D. He, J. Mol. Struct., 2014, 1060, 88.

74. F. Sun and R. Jin, Arab. J. Chem., 2013, 10, 1016.

75. K. Dermeche, N. Tchouar, D. Harkati, S. Belaidi and K. Bentayeb, A. Rouane, Quantum Matter, 2017, 6, 1.

76. F. A. M. Al-Omary, M. Karakaya, Y. Sert, N. G. Haress, A. A. El-Emam and Ç. Çırak, J. Mol. Struct., 2014, 1076, 664.

77. F. Hegelund, R. W. Larsen, R. A. Aitken, K. M. Aitken and M. H. Palmer, J. Mol. Spectrosc., 2007, 246, 198.

78. T. A. Koopmans, J. Chem. Phys., 1993, 1, 104. 